\title{
Emma Goldman e a experiência das mulheres das classes trabalhadoras no Brasil"
}

\section{Cristiana Schettini ${ }^{* *}$}

Neste breve texto, as palavras de Emma Goldman sobre as trabalhadoras que se envolveram com o comércio sexual serão tomadas como um pretexto para uma reflexão sobre algumas questóes relativas à pesquisa do tema no campo da história social $e$, em particular, sobre o lugar que as leis $e$ as fontes judiciais ocuparam na historiografia brasileira sobre prostituição. Como efeito colateral, talvez esta aproximação nos aponte algum caminho para encontrar uma "Emma" que seja, ao mesmo tempo, um pouco familiar e também um pouco estranha aos nossos olhos feministas posicionados a um século de distância. ${ }^{1}$ Para isso, quero retomar algumas redes de interlocução nas quais seu texto pode ser inserido. Depois, passo ao caso brasileiro, para terminar propondo dois exemplos de casos em que a atenção a marcos legais locais e o acesso a fontes judiciais que eles produziram podem revelar alguns sentidos que as histórias de tráfico adquiriram para mulheres que exerceram o comércio sexual no começo do século XX.

Para isso, talvez o mais importante seja começar observando que toda a argumentação de Emma Goldman sobre o tráfico de mulheres está organizada em torno de uma distinção fundamental.

\footnotetext{
" Recebido para publicação em 08 de agosto de 2011, aceito em 16 de setembro de 2011.

** Universidad Nacional de General San Martín. Consejo Nacional de Investigaciones Científicas y Tecnológicas. Instituto Interdisciplinario de Estudios de Género - Universidad de Buenos Aires. cschettini@hotmail.com

1 Sobre as diferentes imagens de Emma Goldman entre as feministas norteamericanas desde os anos 60, ver Frankel (1996:903-942).
}

cadernos pagu (37), julho-dezembro de 2011: 273-285. 
A ironia com que ela abre o texto, fazendo menção à "grande descoberta" do "tráfico de escravas brancas" pelos reformadores norte-americanos, serve para que ela deixe bem claro que uma coisa é a construção social do "problema" do tráfico de mulheres pelos reformadores, intelectuais e cientistas, e outra, bem diversa, é a experiência de jovens trabalhadoras no exercício da prostituição. Essa distinção permite que ela desenvolva suas ideias sobre as consequências da "inferioridade social e econômica" das mulheres sob o capitalismo, expondo a hipocrisia daqueles que protagonizavam cruzadas morais e que faziam as leis $e$ as políticas sobre o comércio sexual. Ao discorrer sobre as causas da prostituição, do tráfico, do sistema de gigolagem, da corrupção policial e das leis moralizadoras, Emma Goldman compartilha alguns aspectos do pensamento de parte de seus contemporâneos que, como ela, também criticavam o sistema de regulamentação. Mas, ao não confundir o conhecimento produzido sobre as prostitutas naquele momento, carregado de preconceitos $e$ moralismos, com a experiência das mulheres da classe trabalhadora que exerciam a prostituição, ela reinterpreta muitos dos dados disponíveis à luz de seu pensamento libertário.

Emma Goldman atribui o "comércio de mulheres" a causas econômicas, muito citadas também nos trabalhos que, desde o século XIX, vinham associando-o à urbanização, imigração $e$ industrialização. Mas ao "fator econômico" se soma a inferioridade social das trabalhadoras (como a trabalhadora doméstica, que nunca tem "direito sobre si mesma"), e principalmente, a "questão sexual", que faz referência ao estado de ignorância permanente em que as mulheres eram mantidas com relação à sua "natureza", aos seus instintos e ao seu corpo. Tal como ocorria com muitos outros militantes de diferentes causas, escritores e cientistas naqueles anos, para Emma Goldman a prostituição era boa para pensar sobre outras coisas. A exploração sexual era comparada à exploração à que estava submetida a classe trabalhadora. A ideia de "vender o corpo" permitia colocar o casamento na mesma linha que a prostituição, 
já que em ambos os casos as mulheres eram tratadas como mercadorias.

Ao falar sobre a prostituição, assim, Emma Goldman não se referia somente às mulheres que trabalhavam no comércio sexual, mas desmontava a sustentação ideológica do mundo norteamericano pós-abolição, em especial as ficções legais em torno ao mercado e aos contratos, vistos como modelo das relações livres naquela sociedade. Em companhia de outros anarquistas $e$ feministas, ela colocava o dedo na ferida da teoria liberal, ao transformar a prostituição num modelo próprio para pensar em relações de exploração e de desigualdade no mundo em que vivia. $^{2}$

Nesse marco geral, não é simples a maneira como Emma Goldman caracteriza as mulheres que exerciam o comércio sexual. Por um lado, suas ações eram entendidas à luz de um contexto em que as mulheres eram impedidas de se realizarem como seres humanos por viver num sistema que as inferiorizava $e$ as mantinha na ignorância, e que além do mais usava seu status como mercadoria para lucrar: era para engordar a renda pública com impostos, e não para controlar a imoralidade, que o Estado entrava no negócio da prostituição. Goldman reconhece, assim, a existência de um potencial humano impedido de se concretizar por culpa de um sistema cruel e violento. Se a conotação da escolha da prostituição por parte das trabalhadoras não deixa de ser fortemente negativa, pelo menos ela torna-se compreensível à luz de tal contexto. Para Goldman, portanto, a prostituição era, ao mesmo tempo, uma condenação de "nossos costumes sociais estúpidos" a quem não se casa, e uma busca por "lazer $e$ esquecimento" e por "diversões baratas" por parte de jovens trabalhadoras. Sua crítica explícita à hipocrisia dos reformadores de seu tempo, juntamente com sua empatia pelas mulheres da

\footnotetext{
2 Para uma excelente análise de como, nos Estados Unidos, as prostitutas passaram a encarnar as ambiguidades da liberdade de contrato definida como negação da escravidão, ver Stanley, 1998, especialmente o capítulo 5.
} 
classe trabalhadora, contribuía para que ela se posicionasse de modo mais compreensivo frente às escolhas dessas mulheres.

Do ponto de vista retórico, a caracterização das trabalhadoras como vítimas, embora também como potencial humano, legitimava sua intervenção política, como militante anarquista, no debate sobre as leis de corte regulamentarista $e$ anti-tráfico. Nesse campo, ela participava de um jogo mais amplo que oscilava entre a vitimização e a culpabilização das mulheres que exerciam o comércio sexual. Iniciado na segunda metade do século XIX, com a regulamentação de casas de tolerância em vários países ocidentais, o debate recrudesceu a partir da aprovação de leis desenhadas especificamente para reprimir o tráfico (e reduzir ainda mais a mobilidade de prostitutas), como o Mann Act nos Estados Unidos, em 1910. ${ }^{3}$ Eram legislações bem distintas. Ao criminalizar a figura inequívoca do gigolô, leis antitráfico eram, pelo menos retoricamente, mais vitimizadoras das prostitutas que as leis regulamentaristas. Isso porque, na regulamentação, ou regime de casas de tolerância, é central a ficção legal de que uma prostituta age por seu livre arbítrio ao colocar-se sob um status legal diferenciado. Já as leis de tráfico, ou a proposta de lei mencionada por Goldman que penalizava "qualquer um que desse abrigo a prostitutas com cinco anos de prisão e dez mil dólares de multa", se sustentam a partir de uma extrema passividade e dependência das mulheres frente à exploração por terceiros. ${ }^{4}$

${ }^{3}$ Conhecida como White Slavery Traffic Act, a lei tornava crime federal o transporte de menores de 18 anos através dos estados norte-americanos com "propósitos imorais" (cf. Rosen, 1982:112-121).

4 Essa diferenciação entre as leis regulamentaristas e as leis anti-tráfico no que se refere à vitimização das prostitutas é trabalhada por White (1990:4 e 5). O código penal brasileiro de 1890, ao introduzir o delito de lenocínio, se prestava a interpretações como esta, mencionada por Goldman. No entanto, as prostitutas puderam, em alguns casos, tirar vantagens desse marco legal. Cf. Schettini, 2006, cap. 1. 
Para Emma Goldman, no entanto, essas sutilezas legais não eram importantes. Tanto as leis regulamentaristas, como as que buscavam a supressão do tráfico, eram igualmente "monstruosas". Ambas tendiam a ser postas "em ação contra a vítima indefesa", ao deixá-la nas mãos da ação ilegal e violenta da polícia. Além disso, Goldman considerava que as cruzadas morais e suas consequentes leis terminavam ratificando o "sistema de gigolagem". Sua completa descrença em qualquer interferência legal no assunto se complementava com a avaliação de que a coisa só se resolveria com um "tratamento mais humano" às prostitutas, juntamente com a "abolição da escravidão industrial".

Emma Goldman se distanciava explicitamente de uma tradição de envolvimento feminino nos debates políticos com base em justificativas morais, embora, de alguma maneira, também fosse herdeira dela. ${ }^{5}$ Em outro artigo da mesma época, ela é ainda mais explícita ao avaliar o que chama da "tragédia da emancipação feminina". Criticando a completa falta de humor das puritanas feministas norte-americanas frente a acusações da imoralidade de suas reivindicações de igualdade de direitos com os homens, ela argumentava que a "verdadeira emancipação" não começaria nem nas urnas, nem nos tribunais. ${ }^{6}$ Coerente com

\footnotetext{
${ }^{5}$ Outras mulheres, antes e depois de Emma Goldman, também legitimaram sua intervenção política em debates sobre direitos das mulheres ao falar em nome de terceiras, das supostas vítimas. Exemplos há por todos os lados, em especial na tradição do feminismo puritano inglês que se opôs à experiência regulamentarista nos centros portuários na Inglaterra, a fins do século XIX. A historiadora Judith Walkowitz (1980:123-124) mostrou como, na Inglaterra, a ideia da escravidão branca e do tráfico de mulheres legitimou a ação de muitas mulheres previamente envolvidas na luta abolicionista, contra a escravidão africana, nas colônias inglesas.

${ }^{6}$ Emma Goldman, 1917. A referência à falta de humor das emancipacionistas frente às acusações de que eram imorais e desrespeitosas das relações entre homens e mulheres, é: "As expoentes dos direitos da mulher ficaram extremamente indignadas frente a uma tamanha distorção, e sem nenhum humor, gastaram toda sua energia em provar que elas não eram de jeito nenhum más como tinham sido pintadas, mas todo o contrário".
} 
seu pensamento anarquista, ela avaliava que esta seria uma questão de "regeneração interna" e individual, de liberação do peso de preconceitos, tradições e costumes que cada mulher arrastava consigo.

O desprezo de Emma Goldman pela interferência estatal, sempre vista como repressiva e coercitiva, e pelas leis, no melhor dos casos, insuficientes, era compartilhado não só por muitos outros anarquistas, como também chegou a seduzir muitos estudos acadêmicos, especialmente em nossas latitudes. ${ }^{7} \mathrm{O}$ militante anarquista brasileiro Astrojildo Pereira, por exemplo, em um artigo contemporâneo aos escritos de Goldman, em que criticava uma proposta de regulamentação do serviço doméstico, era muito claro a esse respeito: "A lei é sempre, absolutamente, tirânica" (Pereira, 1915:10). ${ }^{8}$ Para ele, ao fazer exigências a apenas um dos lados (nesse caso, à empregada doméstica, que deveria portar uma folha de antecedentes) de uma relação composta de duas partes, a lei em questão era "idêntica à da regulamentação da prostituição" em sua injustiça. Pereira terminava o artigo evocando a revolta da vacina a modo de ameaça: se o chefe de polícia se atrevesse a suprimir os direitos "que constituem conquistas populares", que depois não se queixasse com a reação que provocaria. Sua sensibilidade, e a de outros anarquistas, para defender aqueles direitos humanos ameaçados por leis avassaladoras, em alguns momentos também podia servir para defender outros direitos, como aqueles que os trabalhadores esperavam que fossem registrados em lei. Era o caso, por exemplo, a jornada de trabalho de oito horas. ${ }^{9}$

Um pouco diferente foi o lugar que, por muito tempo, a questão da lei e dos direitos ocupou na historiografia que se

\footnotetext{
7 Para uma reflexão mais detida sobre a complexa e ambígua relação dos anarquistas brasileiros com a luta por direitos, ver Oliveira, 2009.

8 Agradeço a Henrique Espada a rápida disponibilização do artigo.

9 Sobre a participação dos diferentes grupos anarquistas ativos em São Paulo na luta pela jornada de oito horas, cf. Toledo, 2007.
} 
dedicou a estudar a prostituição no Brasil. Vimos como Emma Goldman buscava entender a motivação para exercer a prostituição para as trabalhadoras que viviam nos Estados Unidos, associando-a ao "lazer", "diversões baratas" e ao consumismo, mesmo que considerasse a prostituição degradante. Por sua vez, Astrojildo Pereira se aliava aos direitos conquistados pelos trabalhadores, ainda que avaliasse que as leis eram sempre inúteis. Ambos sentiram na pele o peso repressivo da polícia e das leis de seu tempo. No campo da história, esta segunda dimensão foi privilegiada por muito tempo, impedindo os historiadores de atentar para a importância das leis, tanto para as mulheres $e$ homens da classe trabalhadora de outros tempos, como também na sua qualidade de produtoras de fontes (judiciais) para a história social.

Passo a dois breves exemplos. O primeiro, relativo a como a historiografia tratou a ausência de leis regulamentaristas no Brasil. As cidades brasileiras, ao contrário do que aconteceu na vizinha Argentina, jamais aprovaram um regulamento de casas de tolerância. O tema chegou a ser discutido pelo Conselho de Estado em 1876, quando a tendência regulamentarista era forte em muitos países ocidentais, mas nenhuma lei chegou a ser aprovada. ${ }^{10}$ Quando Astrojildo Pereira escrevia seu artigo, em 1915, a regulamentação da prostituição continuava sendo uma ameaça, embora nunca tenha se concretizado. No entanto, para os historiadores que começaram a abordar a prostituição através de fontes médicas, policiais e literárias, parecia ser quase irrelevante que o Brasil não contasse com posturas municipais sobre casas de tolerância. A ausência de um marco legal não parecia ser muito importante frente ao que essa historiografia definiu como um período republicano caracterizado por um

${ }^{10}$ Sobre o debate de 1876, cf. Schettini (2005:25-54). 
acionar policial repressivo e ilegal. ${ }^{11}$ Afinal, que importava se havia ou não uma legislação específica, quando o resultado foi que a prostituição visível terminou concentrada em certos pontos próximos ao centro de muitas cidades, e as prostitutas ficaram a mercê do suborno policial ${ }^{12}$ Lendo teses médicas e relatórios policiais, essa historiografia parece ter obviado o que Emma Goldman gritava em 1917: embora os "reformadores" acreditassem estar "descobrindo" os contornos de um problema social, eles estavam, antes de qualquer coisa, participando ativamente de uma construção ideológica a partir das experiências de trabalho de certos grupos de mulheres. Em outras palavras, seus planos de regulamentar, classificar e controlar nos dizem mais sobre esses homens, e sua busca por legitimidade social, que sobre elas. ${ }^{13}$ A pergunta que essa historiografia não se fez é sobre as razões da impossibilidade política de implementação desses planos e, de forma complementar, sobre as peculiaridades daquilo que terminou sendo implementado.

Essas perguntas podem ter a maior importância para entender quem viveu sob diferentes tipos de sistemas mais ou menos regulamentaristas. A relação de muitas donas de casas de prostituição e de outros acusados de caftismo com a lei e os tribunais é assunto que ainda merece ser mais explorado, e talvez

\footnotetext{
${ }^{11}$ Colocar essa visão em questão não significa ignorar o papel violento $e$ repressivo da polícia na primeira república e em outros momentos da história do Brasil (cf. French, 2006:379-416).

${ }^{12}$ Não era fácil encontrar uma classificação para o que havia no Brasil. $\mathrm{O}$ advogado socialista Evaristo de Moraes (1989:84) considerava, nos anos 20, que a visão policial sobre o tema era "demasiado acanhada" para que o sistema pudesse ser classificado como regulamentarista ou abolicionista. Por sua vez, um delegado, nos anos 70, qualificou o sistema brasileiro de "regulamentarismo mitigado" (cf. Armando Pereira, 1976).

${ }^{13}$ Cf. Engel, 1990, Rago, 1991 e Soares, 1992. Uma excelente crítica a esse aspecto compartilhado pelos três autores foi articulada na resenha de Sandra Graham, "Dangerous fantasies: the altered vocabulary of commercial sex" (1993).
} 
esclareça sobre mecanismos de acumulação, redes sociais e usos da lei por parte de diversos grupos sociais.

Estudos recentes têm levado mais a sério a distinção com que Emma Goldman começou seu texto, entre o alvo de nossas perguntas (as prostitutas de outros tempos) e os meios para respondê-las (as palavras de médicos, juristas, policiais e também literatos de outros tempos). Em diferentes contextos não europeus, muitos autores começaram a criticar a historiografia que se acostumou a estudar a prostituição de uma forma predeterminada por certas tentativas de controle do comércio sexual. ${ }^{14}$

$\mathrm{O}$ segundo exemplo se refere à expulsão de estrangeiros. Emma Goldman foi, ela mesma, deportada para a Rússia em 1919, embora tivesse vivido quase toda sua vida nos Estados Unidos. Astrojildo Pereira presenciou a expulsão de muitos de seus companheiros de militância no marco da lei Adolfo Gordo, aprovada em 1907. Durante muito tempo, parecia que a lei de expulsão foi empregada primordialmente com fins de repressão de militantes políticos, anarquistas em especial. Denunciada como lei inquisitorial, abusiva e inconstitucional por advogados e pelos próprios militantes, a documentação que ela produziu só muito recentemente foi considerada pelos historiadores, que descobriram que ela serviu para enquadrar uma ampla variedade de estrangeiros pobres na categoria de "indesejáveis" (cf. Menezes,

\footnotetext{
${ }^{14}$ Em sua pesquisa sobre a prostituição na Nairobi colonial, Luise White, 1990, descobriu que, para muitas mulheres, a prostituição se transformou num "meio confiável de acumulação de capital", e não só "um destino odioso ou uma estratégia temporária" de sobrevivência. O comportamento econômico dessas prostitutas africanas revelava mecanismos de reprodução familiar, em um contexto no qual a vida urbana e a rural estavam profundamente imbricadas. Ela considera que sua "descoberta" historiográfica não se deve tanto a uma suposta excepcionalidade do caso queniano, mas a uma mudança de estratégia metodológica em relação àquela predominante nos estudos sobre prostituição européia. Cf. também o trabalho de Putnam (2002) sobre as trabalhadoras em Costa Rica que se dedicaram a prostituição, sem nunca desconectar sua experiência do contexto mais amplo da organização regional do trabalho. Para o caso carioca, ver, por exemplo, Kushnir (1996).
} 
1996). Até pouco tempo atrás a lei de expulsão era mencionada primordialmente para reforçar a ideia de uma primeira república que vivia de estados de sítio, na permanente ilegalidade, tratando a questão social com toda a truculência que a polícia local proporcionava. $^{15}$

Para militantes como Emma Goldman e Astrojildo Pereira, podia não ser muito relevante que alguns casos de expulsão seguissem os passos legais previstos e outros fossem diretamente sumários, sem qualquer registro escrito. Mais ou menos formais, sempre seriam parte e prova do estilo arbitrário e violento do poder executivo. Mas para os historiadores, o fato de que alguém tenha deixado algum desses procedimentos por escrito pode, novamente, fazer diferença. Através das sumárias e inquisitoriais investigações policiais prévias à expulsão de um estrangeiro, podemos descobrir, por exemplo, as expectativas de uma prostituta européia ao mudar-se de Buenos Aires para o Rio de Janeiro, depois de ter vivido anos em companhia de um homem do qual ela quis, por alguma razão, se livrar, "despachando-o" de volta para Buenos Aires. ${ }^{16}$

O desafio, nesses dois exemplos, é o de tomar alguma distância de relatos que tendem a ser nossas fontes privilegiadas, como os relatórios policiais e os estudos médicos, mas também de relatos como o de Emma Goldman, para poder formular perguntas que nos aproximem das motivações de homens $e$ mulheres do passado para tomar as decisões que tomaram. Pensando sobre o ainda escasso uso dos registros judiciais como fonte para a história social da prostituição, poderíamos cogitar se parte da razão desse pouco uso guarda alguma relação com a simpatia dos historiadores por relatos com os quais se identificaram. Para avançar com sua luta libertária, e fiéis aos seus princípios, anarquistas como Emma Goldman buscaram entender as motivações e a racionalidade das decisões tomadas pelas

${ }^{15} \mathrm{Cf}$. a excelente discussão de Bonfá, 2008.

${ }^{16}$ Analiso esse e outros casos em Schettini (2010:331-353). 
mulheres que exerceram a prostituição. De certo modo, o desafio dos historiadores sociais agora não é tão distinto: ainda sabemos muito pouco sobre como viveram e que significados atribuíram a suas decisões os homens e mulheres do passado. Mas temos cada vez mais indícios da centralidade da luta por direitos e dos usos dos recursos legais por parte dos trabalhadores que viveram no Brasil na virada para o século XX. Isso faz com que nosso desafio seja, na verdade, muito diferente.

\section{Referências bibliográficas}

BONFÁ, Rogério. Com lei ou sem lei: as expulsões de estrangeiros e o conflito entre o executivo e judiciário na primeira república. Dissertação de Mestrado em História, Unicamp, 2008.

ENGEL, Magali. Meretrizes e doutores: o saber médico e a prostituição na cidade do Rio de Janeiro, 1845-1890. São Paulo, Brasiliense, 1990.

FRANKEL, Oz. Whatever happened to Red Emma? Emma Goldman, from Alien Rebel to American Icon. The Journal of American History, vol. 83, n³, 1996, pp.903-942.

FRENCH, John. Proclamando leis, metendo o pau e lutando por direitos. A questão social como caso de polícia, 1920-1964. In: LARA, Silvia e MENDONÇA, Joseli. Direitos e Justiças no Brasil. Campinas, Ed. da Unicamp, 2006, pp.379-416.

GOLDMAN, Emma. The tragedy of woman's emancipation. In: Anarchism and other essays, 1917. Disponivel em: http://womenshistory.about.com/library/etext/bl eg_ana tragedy_wo mans emancipation.htm Consultado em 26/07/2011.

GRAHAM, Sandra. Dangerous fantasies: the altered vocabulary of commercial sex. Luso-brazilian review, vol.30, n¹, 1993.

KUSHNIR, Beatriz. Baile de Máscaras - mulheres judias e prostituição: as polacas e suas associações de ajuda mútua. Rio de Janeiro, Imago, 1996. 
Emma Goldman e a experiência das mulheres

MENEZES, Lená Medeiros de. Os Indesejáveis - desclassificados da modernidade. Protesto crime e expulsão na capital federal (18901930). Rio de Janeiro, EdUERJ, 1996.

MORAES, Evaristo de. Reminiscências de um rábula criminalista. Rio de Janeiro/Belo Horizonte, Briguiet, 1989.

OliveIRA, Tiago Bernadon de. Anarquismo, sindicatos e revolução no Brasil (1906-1936). Tese de Doutorado em Historia, UFF, 2009.

PEREIRA, Armando. Prostituição: uma visão global. Rio de Janeiro, Ed. Pallas, 1976.

PEREIRA, Astrojildo. Uma monstruosidade que se prepara. A regulamentação do serviço doméstico. A Vida-Periódico Anarquista, n³, ano I, 31 de janeiro de 1915.

PUTNAM, Lara. The Company they kept: migrants and the politics of gender in Caribbean Costa Rica, 1870-1910. Chapel Hill, Univ. of North Carolina Press, 2002.

RAGO, Margareth. Os Prazeres da noite: prostituição e códigos de sexualidade feminina em São Paulo (1890-1930) Rio de Janeiro, Paz e Terra, 1991.

ROSEN, Ruth. The Lost sisterhood: prostitution in América, 1900-1918. Baltimore, Johns Hopkins University Press, 1982.

SCHETTINI, Cristiana. Viajando solas: prácticas de vigilancia policial y experiencias de prostitución en la América del Sur. In: BRETÓN, Jorge Trujillo. (org.) En la Encrucijada. Historia, marginalidad y delito en América Latina y los Estados Unidos de Norteamérica, siglos XIX y XX. Guadalajara, Editorial Universidad de Guadalajara, 2010, pp.331-353.

- Que Tenhas Teu Corpo: uma história social da prostituição no Rio de Janeiro das primeiras décadas republicanas. Rio de Janeiro, Ed. do Arquivo Nacional, 2006.

- Lavar, passar e receber visitas: debates sobre a regulamentação da prostituição e experiências de trabalho sexual em Buenos Aires e no Rio de Janeiro, fim do século XIX. Cadernos Pagu 
(25), Campinas-SP, Núcleo de Estudos de Gênero - Pagu/Unicamp, 2005, pp.25-54.

SOARES, Luis Carlos. Rameiras, ilhoas e polacas: a prostituição no Rio de Janeiro do século XIX. São Paulo, Ática, 1992.

StANLEY, Amy Dru. From Bondage to Contract. Wage labor, marriage and the market in the age of slave emancipation. Cambridge, Cambridge University Press, 1998.

TOLEDO, Edilene. A trajetória anarquista no Brasil na Primeira República. In: FERREIRA, Jorge e AARÃO, Daniela Reis. As Esquerdas no Brasil. A formação das tradições (1889-1945) Rio de Janeiro, Civilização Brasileira, 2007.

WALKOWITZ, J. Prostitution and the Victorian Society: women, class and the state. Cambridge, Cambdridge University Press, 1980, pp.123124

WhITE, Luise. The Comforts of Home: prostitution in Colonial Nairobi. Chicago, University of Chicago Press, pp.4 e 5. 